\title{
Effects of a single treatment with two nonthermal laser wavelengths on chronic neck and shoulder pain
}

This article was published in the following Dove Press journal: Medical Devices: Evidence and Research

\author{
Robert G Silverman' \\ Albert Comey ${ }^{2}$ \\ Travis Sammons ${ }^{3}$ \\ 'Clinical Study Site, New York \\ ChiroCare, White Plains, NY, USA; \\ ${ }^{2}$ Clinical Study Site, Comey Chiropractic \\ Clinic, Largo, FL, USA; ${ }^{3}$ Erchonia \\ Corporation, Melbourne, FL, USA
}

\begin{abstract}
Introduction: Nonthermal lasers provide pain relief for a variety of musculoskeletal disorders and improve physical functioning. A nonthermal laser that employs a $635 \mathrm{~nm}$ red diode is cleared for the temporary reduction of neck and shoulder pain of musculoskeletal origin. As a $405 \mathrm{~nm}$ violet laser has shown synergy with the $635 \mathrm{~nm}$ red laser when used together for treating other conditions, the objective of this study was to compare the efficacy of $635 \mathrm{~nm}$ red and $405 \mathrm{~nm}$ violet lasers vs the $635 \mathrm{~nm}$ red laser for treating neck and shoulder pain of musculoskeletal origin.
\end{abstract}

Materials and methods: Otherwise healthy adult subjects with chronic neck or shoulder pain for $\geq 30$ days were enrolled and randomized to receive a single 13-min treatment with combined red and violet lasers $(n=44)$ or the red laser alone $(n=43)$. The primary efficacy measure was change in baseline VAS pain scores 3 mins after treatment. Subject success was predefined as a $\geq 30 \%$ decrease in VAS scores and study success was predefined as $65 \pm 5 \%$ individual subject successes.

Results: Among subjects treated with the red and violet lasers, mean VAS neck and shoulder pain scores decreased from 65.0 to $35.2(p<0.0001)$. Most subjects in the study $(75 \%)$ achieved $\geq 30 \%$ decrease in VAS scores. The decreased mean (SD) VAS scores remained 29.6 (16.7) and 29.3 (19.2) after 24 and $48 \mathrm{hrs}$, respectively. The secondary efficacy measures of change in range of motion ROM) and patient satisfaction also improved. There were no adverse events.

Conclusion: Overall, treatment with the red and violet lasers outperformed the FDA-approved red laser with respect to change in pain scores and improvement in shoulder ROM.

Keywords: nonthermal laser, low-level laser, chronic pain, randomized trial

\section{Introduction}

Nonthermal or low-level lasers can be used to stimulate mitochondrial chromophores - specifically cytochrome $\mathrm{C}$ oxidase - to achieve a therapeutic effect. ${ }^{1,2}$ Nonthermal lasers have been shown to enhance the healing of bone fractures, 3,4 burns $^{5,6}$ and diabetic ulcers, ${ }^{7,8}$ stimulate nerve regeneration ${ }^{9}$ and even treat acne vulgaris by its effect on Propionibacterium acnes. ${ }^{10}$ Nonthermal lasers have also been shown to treat a variety of painful musculoskeletal disorders ${ }^{11}$ including neck and shoulder pain $^{12,13}$ and can provide relief from pain for 2-6 months after treatment. ${ }^{14}$ In one study, relief from plantar fasciitis persisted for 12 months. $^{15}$
Correspondence: Travis Sammons

Erchonia Corporation, 650 Atlantis Road Melbourne, FL 32904, USA

Tel + I $32|473| 25 \mid$

Fax + I 321 4731608

Email TSammons@erchonia.com 
A systematic review and meta-regression analysis found treatment with nonthermal lasers to be more beneficial than placebo for chronic neck pain ${ }^{16}$ and improving physical functioning and quality of life. ${ }^{17}$

A randomized, double-blind, sham-controlled trial assessed the efficacy of a $635 \mathrm{~nm}$ red nonthermal laser for treating subjects with chronic shoulder and neck pain $(N=86) .{ }^{13}$ A single 1 min treatment was applied to 12 sites on the neck and shoulders. A VAS was used to measure changes in pain perception immediately after treatment. Among laser-treated subjects, $65.1 \%$ met the criteria for treatment success, defined as a $30 \%$ decrease in VAS pain scores vs $11.6 \%$ among sham-treated subjects $(p<0.0001)$. Mean VAS scores decreased from 60.2 to $31.2(p<0.0001)$ for Low-level laser (light) therapy (LLLT)-treated subjects vs $60.0-55.1$ for sham-treated subjects $(p=\mathrm{NS})$. The mean between-group difference in post-treatment VAS scores was 24.1 points $(p<0.005)$. There was also a significant improvement in range of motion (ROM) among lasertreated subjects but not sham-treated subjects. These results supported the $510(\mathrm{k})$ clearance of this $635 \mathrm{~nm}$ red diode device for the temporary reduction of neck and shoulder pain of musculoskeletal origin. ${ }^{18}$

The $405 \mathrm{~nm}$ violet laser has also demonstrated a variety of beneficial effects, such as wound healing ${ }^{19-21}$ and antimicrobial effects. ${ }^{22-25}$ Although it has not been previously studied for painful conditions, the $405 \mathrm{~nm}$ violet laser has shown synergy with the therapeutic effects of a $635 \mathrm{~nm}$ red laser when the two diodes are used simultaneously. ${ }^{26}$ The objective of this nonrandomized noninferiority design was to compare the efficacy of combining $635 \mathrm{~nm}$ red- and $405 \mathrm{~nm}$ violet-emitting diodes for treating neck and shoulder pain of musculoskeletal origin versus treatment with the $635 \mathrm{~nm}$ red diode alone.

\section{Methods}

\section{Study subjects}

Study subjects $\geq 18$ years old were recruited from among the investigators' pool of patients seeking treatment for neck and shoulder pain, and from among individuals responding to locally placed recruitment flyers and print ads. Each subject provided written informed consent prior to participating in any study-related activities. This study was conducted in accordance with the Declaration of Helsinki. Subjects received no compensation for their participation.
Subjects were required to have symptoms of chronic neck or shoulder pain caused by osteoarthritic degenerative joint disorder, chronic muscle spasms, cervical and thoracic spine sprain strain based on medication use history, medical records including $\mathrm{x}$-ray, magnetic resonance imaging and CAT scan reports and physical examination. Symptoms were considered chronic if they persisted for $\geq 30$ days.

Subjects expressed their willingness to refrain from using over-the-counter (OTC) or prescription medication or herbal supplements intended for the relief of pain or inflammation, including muscle relaxants, for the duration of the study and refrain from other therapies for neck or shoulder pain including physical therapy, occupational therapy, hot or cold packs or alternative therapies, such as chiropractic care and acupuncture for the duration of the study.

Subjects were excluded from participation if they presented with primary pain located outside or in addition to the region of the neck or the shoulder; the etiology of neck or shoulder pain could not be definitively diagnosed or was due to other than osteoarthritis, chronic muscle spasms or cervical and thoracic spine sprain strain, or if other potential contributing etiologies could not be satisfactorily ruled out; acute pain symptoms; active chronic pain disease such as chronic fatigue syndrome or fibromyalgia; analgesic or muscle relaxant use within 7 days prior to study treatment; use of systemic corticosteroids not including inhaled and topical products; use of narcotics or botulinum toxin injection in the neck or shoulder within 30 days prior to study treatment; cancer or treatment for cancer within the last 6 months; unstable cardiac disease, such as cardiac arrhythmia, congestive heart failure or myocardial infarction; prior neck or shoulder surgery or herniated disc injury; active infection, wound or other external trauma in the planned treatment area; any medical or physical contraindications to light therapy; serious mental health illness such as dementia, schizophrenia or psychiatric hospitalization in the past 2 years; pregnancy, breastfeeding or planned pregnancy; participation in a research study within the past 30 days.

\section{Study device}

The device used in this study was a hand-held, low-level nonthermal laser that uses a $635 \mathrm{~nm}$ semiconductor diode (visible red light) and a $405 \mathrm{~nm}$ semiconductor diode (visible violet light), each emitting its respective wavelength with a tolerance of $\pm 10 \mathrm{~nm}$ (Erchonia ${ }^{\circledR}$ Model 
EVRL) ${ }^{27}$ The device is configured with one $7.5 \mathrm{~mW}$ linegenerated red laser diode and one $<5 \mathrm{~mW}$ line-generated violet laser diode with patented optics. The total amount of applied energy was $4.68 \mathrm{~J}$. Safety glasses were provided to subjects and investigators for use during all treatment procedures (C22-KMT-6101 laser safety glasses; Kentek Corporation, Pittsfield, NH, USA).

\section{Study procedure}

Subjects received a single 13-min treatment with the nonthermal laser device on the day of study enrollment. Overall, the treatment protocol was identical to the protocol previously used with the single red $635 \mathrm{~nm}$ diode. ${ }^{13}$

\section{Study endpoints}

Baseline evaluation of each subject was performed on the day of study enrollment and included demographics, neck and shoulder VAS pain scores and linear ROM measurements. The VAS is a $100 \mathrm{~mm}$ horizontal line on which the patient's pain intensity is represented by a point between the extremes of "no pain at all" and "worst pain imaginable" which is sensitive to treatment effects. ${ }^{28}$ Evaluation was repeated 3 mins, 24- and $48 \mathrm{hrs}$ following administration of the laser treatment.

The primary measure of efficacy was the change in baseline neck and shoulder VAS pain scores within 3 mins after treatment. Subject treatment success was predefined as a $\geq 30 \%$ decrease in VAS scores. Overall study success was predefined as $65 \pm 5 \%$ individual subject successes. As this was a noninferiority study, the efficacy of the red/ violet diode device was compared with the prior red 635 $\mathrm{nm}$ diode device. Change in mean neck and shoulder VAS pain scores was assessed using a two-sample $t$-test for correlated samples.

Subject satisfaction was assessed using a 5-point Likert scale ranging from "Very Satisfied" to "Not at All Satisfied" in response to the question "Overall, how satisfied or dissatisfied are you with any change in the pain in your neck and/or shoulder following the study procedure with the study laser device?" at the 24- and 48-hr assessments.

The primary safety endpoint was reports of adverse events at any time during the study.

\section{Ethics}

The protocol used in this study was approved by a commercial institutional review board (Western Institutional
Review Board $^{\circledR}$, Puyallup, WA; Study Numbers $1,184,868$ [Silverman] and 1,185,325 [Comey]).

\section{Results}

\section{Subject demographics and clinical characteristics}

Forty-four (44) subjects were enrolled and completed the study. Subjects were male $(\mathrm{n}=17 ; 39 \%)$ and female $(\mathrm{n}=27$; $61 \%$ ) with a mean (SD) age of 54.1 (14.3) years (range, 27-82 years). Subjects described themselves as Caucasian $(\mathrm{n}=36 ; 82 \%)$, Hispanic $(\mathrm{n}=2 ; 4.5 \%)$, Asian $(\mathrm{n}=2 ; 4.5 \%)$, African-American $(n=1 ; 2 \%)$ or other $(n=3 ; 7 \%)$.

Pain location on the neck was on the right side ( $\mathrm{n}=29$, $66 \%)$, left side $(n=29,66 \%)$, or back $(n=26,57 \%)$ and shoulder pain was right $(\mathrm{n}=27,61 \%)$ and left $(\mathrm{n}=20,45 \%)$ which were all of musculoskeletal origin. Duration of neck and shoulder pain was 76.6 (110.8) months (range, 1.5468 months). Mean VAS pain rating at study entry was 65.0 on the 100-point VAS. Prior OTC and/or prescription analgesic use $(n=23,52 \%)$ to relieve neck/shoulder pain consisted of one $(n=16)$, two $(n=4)$ or three $(n=2)$ medications (Table 1).

\section{Efficacy}

The primary efficacy measure, mean VAS neck and shoulder pain scores, decreased from 65.0 to 35.2. A $t$-test for correlated samples showed a mean decrease of 29.8 points to be significant $(p<0.0001)$. Most subjects in the study (75\%) achieved $\geq 30 \%$ decrease in VAS scores, exceeding the overall study success criteria by $5 \%$ (Table 2). Among subjects achieving individual treatment success $(n=33)$, the mean baseline VAS scores decreased from 63.9 (8.7) to 27.5 (10.9) a mean decrease of 36.4 (13.4) points, or $56.4(17.2) \%(p<0.0001)$. The reduced mean VAS scores remained 29.6 (16.7) and 29.3 (19.2)

Table I Prescription and over-the-counter analgesics

\begin{tabular}{|l|l|}
\hline Medication & $\mathbf{n}(\%)^{\mathbf{a}}$ \\
\hline Ibuprofen & $\mathrm{I} 3(43)$ \\
Naproxen & $\mathrm{II}(37)$ \\
Aspirin & $\mathrm{I}(3.3)$ \\
Aspirin/caffeine & $\mathrm{I}(3.3)$ \\
Capsaicin patch & $\mathrm{I}(3.3)$ \\
Celecoxib & $\mathrm{I}(3.3)$ \\
Tramadol & $\mathrm{I}(3.3)$ \\
Diclofenac gel & $\mathrm{I}(3.3)$ \\
\hline
\end{tabular}

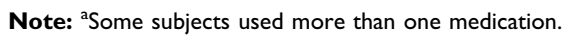


Table 2 Change is visual analog pain scores

\begin{tabular}{|l|l|l|}
\hline \multirow{2}{*}{ Timepoint } & Dual diode, N=44 & $\begin{array}{l}\text { Single diode, } \\
\mathbf{N}=43\end{array}$ \\
\cline { 2 - 3 } & Mean (SD) & Mean (SD) \\
\hline Pretreatment & $65.0(8.4)$ & $60.2(9.8)$ \\
3 mins post-treatment & $35.2(17.0)$ & $31.2(18.7)$ \\
24 hrs post-treatment & $34.6(17.6)$ & $34.0(24.6)^{\mathrm{a}}$ \\
48 hrs post-treatment & $32.3(19.9)$ & $34.2(23.9)^{\mathrm{a}}$ \\
\hline
\end{tabular}

Note: ${ }^{\mathrm{a}} \mathrm{N}=34$.

after 24 and $48 \mathrm{hrs}$, respectively (Figure 1). With only one subject failing to respond to treatment, the overall response rate was $97.7 \%$.

The secondary efficacy measure, neck and shoulder ROM, also showed improvement. Mean seated passive abduction improved 27.9 degrees on both sides, mean shoulder measurements in relaxed position improved 30.1 degrees on the right side and 28.5 degrees on the left side and mean neck ROM measurements improved 22.7 and 23.4 degrees for the right and left sides, respectively (Table 3). Overall, subjects achieved a mean 29.07\% improvement in neck and shoulder ROM. Among subjects achieving individual treatment success, there was no additional improvement in ROM outcomes. A comparison of clinical outcomes following treatment with the violet and red lasers vs the red laser alone is summarized in Table 4.

The proportion of subjects who were "Very Satisfied" with an overall change in neck and shoulder pain increased from $41 \%$ at endpoint evaluation to $46 \%$ at 48 hrs postprocedure evaluation and $71 \%$ of subjects were "Very Satisfied" or "Somewhat Satisfied" (Table 5). One subject who did not achieve a $\geq 30 \%$ decrease in VAS scores remained "Very Satisfied" with treatment outcome at 48 hrs.

\section{Safety}

No adverse events were reported by any subject throughout the study duration.

\section{Discussion}

The process of LLLT is based on a photochemical reaction with light in the visible spectrum (380-700 nm) to achieve therapeutic effects. This occurs when a suitable chromophore absorbs a photon of light and an electron is elevated to an excited state. ${ }^{30}$ One such chromophore is the enzyme cytochrome $\mathrm{C}$ oxidase in the mitochondrial respiratory chain, with peak absorption found in the red to near-infrared spectrum. ${ }^{29}$ The therapeutic effects of LLLT occur when the inhibitory signaling molecule nitric oxide becomes dissociated from cytochrome $\mathrm{C}$ oxidase. This results in increased electron transport, mitochondrial membrane potentials and production of mitochondrial ATP, NADH, RNA and cellular respiration. ${ }^{31,32}$

The objective of this study was to determine whether combining $405 \mathrm{~nm}$ violet and $635 \mathrm{~nm}$ red lasers are equivalent or superior to the $635 \mathrm{~nm}$ red laser alone for the treatment of chronic neck and shoulder pain. The 635 $\mathrm{nm}$ device was previously FDA cleared for the temporary reduction of neck and shoulder pain of musculoskeletal origin; however, this is the first clinical study to demonstrate the effectiveness of a wavelength lower than $635 \mathrm{~nm}$ for treating musculoskeletal pain. Overall, the violet and red laser combination was superior to the red laser in most clinical measures. Although subjects treated with violet and red laser device had higher baseline pain scores, they

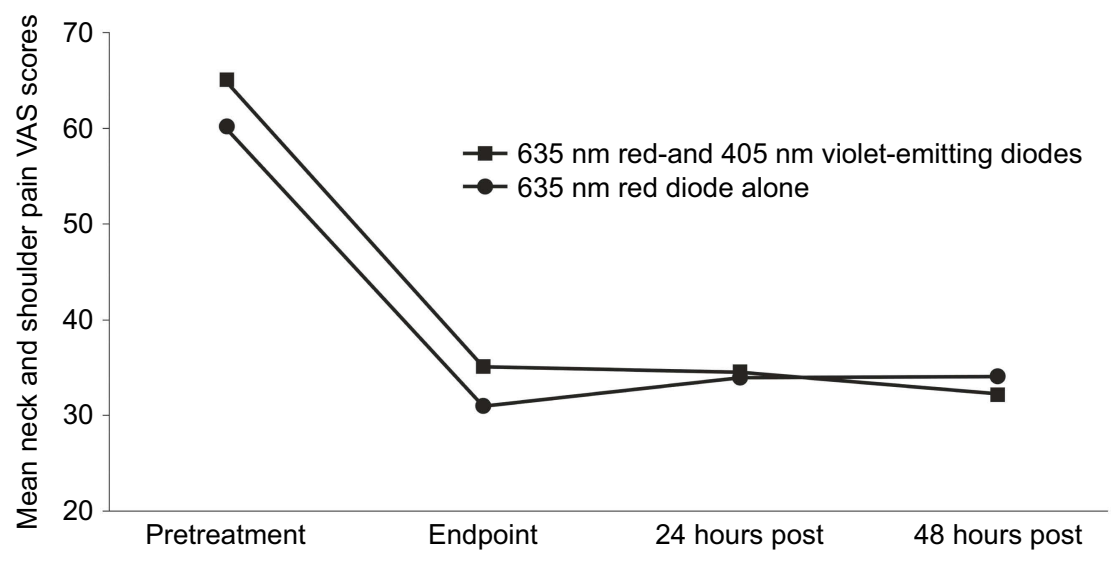

Figure I Change in VAS pain scores following treatment. Following treatment with $635 \mathrm{~nm}$ red- and 405 nm violet-emitting diodes, the neck and shoulder VAS scores decreased from 65.0 to 35 ( $p<0.0001$ ), a decrease of 29.8 points vs a decrease of 29.0 points for the $635 \mathrm{~nm}$ red diode alone. 
Table 3 Change in range of motion

\begin{tabular}{|c|l|l|}
\hline \multirow{2}{*}{$\begin{array}{l}\text { Seated passive shoulder } \\
\text { abduction }\end{array}$} & Right side & Left side \\
\cline { 2 - 3 } & $\begin{array}{l}\text { Degrees, } \\
\text { mean (SD) }\end{array}$ & $\begin{array}{l}\text { Degrees, } \\
\text { mean (SD) }\end{array}$ \\
\hline Pretreatment & $134.7(26.4)$ & $137.6(24.7)$ \\
Endpoint (3 mins) & $162.6(16.1)$ & $165.6($ I3.9) \\
Change & $27.9($ I6.9) & $27.9($ I7.3) \\
\hline Relaxed shoulder position & Mean (SD) & Mean (SD) \\
Pretreatment & $131.0(26.6)$ & $135.2(24.3)$ \\
Endpoint (3 mins) & $161.1(21.0)$ & $163.8($ I8.I) \\
Change & $30.1($ I4.6) & $28.5($ I5.2) \\
\hline Neck & Mean (SD) & Mean (SD) \\
Pretreatment & $52.6($ I3.1) & $51.1($ I4.9) \\
Endpoint (3 mins) & $75.2(9.6)$ & $74.4($ I2.0) \\
Change & $22.7(9.6)$ & $23.4(9.2)$ \\
\hline
\end{tabular}

Table 4 Clinical outcomes of violet and red lasers versus red laser only

\begin{tabular}{|c|c|c|c|}
\hline & $\begin{array}{l}\text { Violet } \\
\text { and red } \\
\text { lasers }\end{array}$ & $\begin{array}{l}\text { Red } \\
\text { laser } \\
\text { only }\end{array}$ & Difference \\
\hline & $N=44$ & $N=43$ & \\
\hline Duration of pain, months & 110.8 & 61.7 & 49.1 \\
\hline $\begin{array}{l}\text { Change in shoulder range of } \\
\text { motion, degrees }\end{array}$ & $29.3^{\circ}$ & $14.4^{\circ}$ & $14.9^{\circ}$ \\
\hline $\begin{array}{l}\text { Change in VAS immediately } \\
\text { after treatment }\end{array}$ & 29.8 & 29.0 & 0.8 \\
\hline $\begin{array}{l}\text { Subjects meeting study success } \\
\text { criteria, } \geq 30 \% \text { pain reduction }\end{array}$ & $75 \%$ & $65 \%$ & $10 \%$ \\
\hline $\begin{array}{l}\text { Percent improvement from } \\
\text { study endpoint to } 48 \text { hrs post- } \\
\text { treatment }\end{array}$ & $+8.13 \%$ & $-9.01 \%$ & $17.14 \%$ \\
\hline
\end{tabular}

Table 5 Subject post-treatment satisfaction

\begin{tabular}{|c|c|c|c|}
\hline Satisfaction & $\begin{array}{l}3 \text { mins n } \\
(\%)\end{array}$ & $\begin{array}{l}24 \text { hrs n } \\
\text { (\%) }\end{array}$ & $\begin{array}{l}48 \text { hrs n } \\
\text { (\%) }\end{array}$ \\
\hline Very satisfied & $18(4 \mid)$ & $17(39)$ & $20(46)$ \\
\hline Somewhat satisfied & $21(48)$ & $14(32)$ & II (25) \\
\hline $\begin{array}{l}\text { Neither satisfied nor } \\
\text { dissatisfied }\end{array}$ & $9(\mathrm{II})$ & $8(18)$ & $5(\mathrm{II})$ \\
\hline Not very satisfied & - & $3(7)$ & $6(14)$ \\
\hline Not at all satisfied & - & $2(4)$ & $2(4)$ \\
\hline
\end{tabular}

achieved a greater reduction in pain scores and improved ROM.

In a previous study, a $635 \mathrm{~nm}$ laser device significantly reduced plantar fasciitis pain following two weekly treatments for 3 weeks. ${ }^{33}$ In the present study, therapeutic benefit was achieved with a single treatment session. Mean neck and shoulder VAS pain scores decreased from 65.0 to 35.2, a mean decrease of 29.8 points $(p<0.0001)$. Most subjects in the study (75\%) achieved $\geq 30 \%$ decrease in VAS scores, exceeding the overall study success criteria. In the previous $635 \mathrm{~nm}$ study, sham-controlled study, mean VAS neck and shoulder pain scores decreased from 60.2 to 31.2, a mean 29.0-point decrease $(p<0.0001) .{ }^{13}$ In that study, $65.1 \%$ of the treated subjects achieved $\geq 30 \%$ decrease in VAS scores (Table 2). Overall, the violet and red laser combination was superior to the red laser in every clinical measure.

These data were used to support the $510(\mathrm{k})$ clearance of a $405 \mathrm{~nm}$ violet/635 $\mathrm{nm}$ red laser device for the temporary reduction of neck and shoulder pain of musculoskeletal origin. $^{27}$

The results of this single treatment clinical trial add to the existing body of data demonstrating the ability of nonthermal lasers to alleviate pain associated with chronic joint disorders, ${ }^{34}$ chronic low back pain, ${ }^{35}$ neck pain, ${ }^{16,17}$ adhesive capsulitis (frozen shoulder) ${ }^{36}$ and pain from a variety of musculoskeletal and orthopedic injuries and procedures. $^{25,31,37}$

As nonthermal lasers have demonstrated efficacy without any known adverse effects, and there is little evidence supporting the long-term use of opioids for chronic pain, ${ }^{38}$ lasers should be considered as a first step for treating chronic musculoskeletal pain.

\section{Conclusion}

A novel, low-level nonthermal laser that combines red 635 $\mathrm{nm}$ and violet $405 \mathrm{~nm}$ semiconductor diodes was used to treat subjects with neck and shoulder pain of musculoskeletal origin. A single treatment resulted in diminished pain scores in $75 \%$ of subjects with increased ROM and overall subject satisfaction. Treatment with the red and violet lasers outperformed the FDA-approved red laser with respect to pains scores and improvement in shoulder ROM.

\section{Acknowledgments}

The authors acknowledge the editorial assistance of Dr. Carl S. Hornfeldt, Apothekon, Inc., during the preparation of this manuscript. This study was sponsored by Erchonia Corporation, Melbourne, FL, USA. 


\section{Disclosure}

$\mathrm{Mr}$ Travis Sammons is an employee of Erchonia Corporation. The authors report no other conflicts of interest in this work.

\section{References}

1. Chung H, Dai T, Sharma SK, Huang YY, Carroll JD, Hamblin MR. The nuts and bolts of low-level laser (light) therapy. Ann Biomed Eng. 2012;40:516-533. doi:10.1007/s10439-011-0454-7

2. Hamblin MR. Mechanisms and mitochondrial redox signaling in photobiomodulation. Photochem Photobiol. 2018;94:199-212. doi:10.1111/php.12864

3. Neto FCJ, Martimbianco ALC, de Andrade RP, Bussadori SK, Mesquita-Ferrari RA, Fernandes KPS. Effects of photobiomodulation in the treatment of fractures: a systematic review and meta-analysis of randomized clinical trials. Lasers Med Sci. 2019. [Epub ahead of print]. doi:10.1007/s10103-019-02779-4

4. Hosseinpour S, Fekrazad R, Arany PR, Ye Q. Molecular impacts of photobiomodulation on bone regeneration: a systematic review. Prog Biophys Mol Biol. 2019;6107:30017.

5. Yadav A, Verma S, Keshri GK, Gupta A. Combination of medicinal honey and $904 \mathrm{~nm}$ superpulsed laser-mediated photobiomodulation promotes healing and impedes inflammation, pain in full-thickness burn. J Photochem Photobiol B. 2018;186:152-159. doi:10.1016/j. jphotobiol.2018.07.008

6. Lamaro-Cardoso A, Bachion MM, Morais JM, et al. Photobiomodulation associated to cellular therapy improve wound healing of experimental full thickness burn wounds in rats. $J$ Photochem Photobiol B. 2019;194:174-182. doi:10.1016/j.jphotobiol.2019.04.003

7. Jere SW, Houreld NN, Abrahamse H. Role of the PI3K/AKT (mTOR and GSK $3 \beta$ ) signalling pathway and photobiomodulation in diabetic wound healing. Cytokine Growth Factor Rev. 2019;S13596101:30013-30019.

8. Maiya AG, Kumar AS, Hazari A, et al. Photobiomodulation therapy in neuroischaemic diabetic foot ulcers: a novel method of limb salvage. J Wound Care. 2018;27:837-842. doi:10.12968/jowc.2018. 27.12.837

9. Rosso MPO, Buchaim DV, Kawano N, Furlanette G, Pomini KT, Buchaim RL. Photobiomodulation therapy (PBMT) in peripheral nerve regeneration: a systematic review. Bioengineering. 2018;5: E44. doi:10.3390/bioengineering5020044

10. Boyd JM, Lewis KA, Mohammed N, et al. Propionibacterium acnes susceptibility to low-level $449 \mathrm{~nm}$ blue light photobiomodulation. Lasers Surg Med. 2019. [Epub ahead of print]. doi:10.1002/ $1 \mathrm{sm} .23087$

11. Clijsen R, Brunner A, Barbero M, Clarys P, Taeymans J. Effects of low-level laser therapy on pain in patients with musculoskeletal disorders: a systematic review and meta-analysis. Eur J Phys Rehabil Med. 2017;53:603-610. doi:10.23736/S1973-9087.17.044 32-X

12. Takahashi H, Okuni I, Ushigome N, et al. Low level laser therapy for patients with cervical disk hernia. Laser Ther. 2012;21:193-197. doi:10.5978/islsm.12-OR-10

13. Roche GC, Murphy DJ, Berry TS, Shanks S. Low-level laser therapy for the treatment of chronic neck and shoulder pain. Funct Neurol Rehabil Ergo. 2016;6:97-104.

14. Swedish Council on Health Technology Assessment. Laser treatment of neck pain [Internet]. SBU Alert Report No. 2014-03. SBU Systematic Review Summaries. Stockholm: Swedish Council on Health Technology Assessment (SBU); 2014 May. Available from: https://www.sbu.se/en/publications/sbu-assesses/laser-treatment-ofneck-pain/. Accessed February 05, 2019.
15. Jastifer JR, Catena F, Doty JF, Stevens F, Coughlin MJ. Low-level laser therapy for the treatment of chronic plantar fasciitis: a prospective study. Foot Ankle Int. 2014;35:566-571. doi:10.1177/1071100714523275

16. Chow RT, Johnson MI, Lopes-Martins RA, Bjordal JM. Efficacy of low-level laser therapy in the management of neck pain: a systematic review and meta-analysis of randomised placebo or active-treatment controlled trials. Lancet. 2009;374:1897-1908. doi:10.1016/S01406736(09)61522-1

17. Gross AR, Dziengo S, Boers O, et al. Low level laser therapy (LLLT) for neck pain: a systematic review and meta-regression. Open Orthop J. 2013;7:396-419. doi:10.2174/1874325001307010396

18. Roche GC, Murphy DJ, Berry TS, Shanks S. Low-level Laser Therapy for the Treatment of Chronic Neck and Shoulder Pain. Funct Neurol Rehabil Ergon. 2016;6(2):97-104.

19. Tani A, Chellini F, Giannelli M, Nosi D, Zecchi-Orlandini S, Sassoli C. Red $(635 \mathrm{~nm})$, near-infrared $(808 \mathrm{~nm})$ and violet-blue $(405 \mathrm{~nm})$ photobiomodulation potentiality on human osteoblasts and mesenchymal stromal cells: a morphological and molecular in vitro study. Int $J$ Mol Sci. 2018;19:E1946. doi:10.3390/ ijms19071946

20. Mosca RC, Ong AA, Albasha O, Bass K, Arany P. Photobiomodulation therapy for wound care: a potent, noninvasive, photoceutical approach. Adv Skin Wound Care. 2019;32:157-167. doi:10.1097/01.ASW.0000553600.97572.d2

21. McDonald R, Macgregor SJ, Anderson JG, Maclean M, Grant MH. Effect of 405-nm high-intensity narrow-spectrum light on fibroblastpopulated collagen lattices: an in vitro model of wound healing. $J$ Biomed Opt. 2011;16:048003. doi:10.1117/1.3561903

22. Enwemeka CS, Williams D, Hollosi S, Yens D, Enwemeka SK. Visible $405 \mathrm{~nm}$ SLD light photo-destroys methicillin-resistant staphylococcus aureus (MRSA) in vitro. Lasers Surg Med. 2008;40:734-737. doi:10.1002/1sm.20724

23. Sevgi M, Toklu A, Vecchio D, Hamblin MR. Topical antimicrobials for burn infections - an update. Recent Pat Antiinfect Drug Discov. 2013;8:161-197.

24. Dai T, Gupta A, Huang YY, et al. Blue light eliminates communityacquired methicillin-resistant staphylococcus aureus in infected mouse skin abrasions. Photomed Laser Surg. 2013;31:531-538. doi:10.1089/pho.2012.3365

25. Zang K, Sullivan R, Shanks S. A retrospective study of non-thermal laser therapy for the treatment of toenail onychomycosis. $J$ Clin Aesthet Dermatol. 2017;10:24-30.

26. O'Connor M, Patil R, Yu J, et al. Mesenchymal stem cells synergize with 635,532 , and $405 \mathrm{~nm}$ laser wavelengths in renal fibrosis: a pilot study. Photomed Laser Surg. 2016;34:556-563. doi:10.1089/pho.2015.4025

27. EVRL Violet Laser System Data Sheet. Revised, 2016. Melbourne, FL: Erchonia ${ }^{\circledR}$ Corporation; 2016.

28. Haefeli M, Elfering A. Pain assessment. Eur Spine J. 2006;15:S17S24. doi:10.1007/s00586-005-1044-x

29. Karu TI, Afanasyeva NI. Cytochrome C oxidase as primary photoacceptor for cultured cells in visible and near IR regions. Doklady Akad Nauk. 1995;342:693-695.

30. Cotler HB, Chow RT, Hamblin MR, Carroll J. The use of low level laser therapy (LLLT) for musculoskeletal pain. MOJ Orthop Rheumatol. 2015;2(5). doi:10.15406/mojor.2015.02.00068

31. de Freitas LF, Hamblin MR. Proposed mechanisms of photobiomodulation or low-level light therapy. IEEE J Sel Top Quantum Electron. 2016;22:7000417. doi:10.1109/JSTQE.2016.2561201

32. Wang X, Tian F, Soni SS, Gonzalez-Lima F, Liu H. Interplay between up-regulation of cytochrome-c-oxidase and hemoglobin oxygenation induced by nearinfrared laser. Sci Rep. 2016;6:30540. doi:10.1038/srep30540

33. Macias DM, Coughlin MJ, Zang K, Stevens FR, Jastifer JR, Doty JF. Low-level laser therapy at $635 \mathrm{~nm}$ for treatment of chronic plantar fasciitis: a placebo-controlled, randomized study. J Foot Ankle Surg. 2015;54:768-772. doi:10.1053/j.jfas.2014.12.014 
34. Bjordal JM, Couppé C, Chow RT, Tunér J, Ljunggren EA. A systematic review of low level laser therapy with location-specific doses for pain from chronic joint disorders. Aust $J$ Physiother. 2003;49:107-116.

35. Huang Z, Ma J, Chen J, Shen B, Pei F, Kraus VB. The effectiveness of low-level laser therapy for nonspecific chronic low back pain: a systematic review and meta-analysis. Arthritis Res Ther. 2015;17:360. doi:10.1186/s13075-015-0882-0

36. Ip D, Fu NY. Two-year follow-up of low-level laser therapy for elderly with painful adhesive capsulitis of the shoulder. J Pain Res. 2015;8:247-252. doi:10.2147/JPR.S84376
37. Langella LG, Casalechi HL, Tomazoni SS, et al. Photobiomodulation therapy (PBMT) on acute pain and inflammation in patients who underwent total hip arthroplasty-a randomized, triple-blind, placebocontrolled clinical trial. Lasers Med Sci. 2018;33:1933-1940. doi:10.1007/s10103-018-2558-X

38. Meske DS, Lawal OD, Elder H, Langberg V, Paillard F, Katz N. Efficacy of opioids versus placebo in chronic pain: a systematic review and meta-analysis of enriched enrollment randomized withdrawal trials. J Pain Res. 2018;11:923-934. doi:10.2147/JPR.S160255
Medical Devices: Evidence and Research

\section{Publish your work in this journal}

Medical Devices: Evidence and Research is an international, peerreviewed, open access journal that focuses on the evidence, technology, research, and expert opinion supporting the use and application of medical devices in the diagnosis, monitoring, treatment and management of clinical conditions and physiological processes. The identification of novel devices and optimal use of existing devices

\section{Dovepress}

which will lead to improved clinical outcomes and more effective patient management and safety is a key feature of the journal. The manuscript management system is completely online and includes a very quick and fair peer-review system. Visit http:// www.dovepress.com/testimonials.php to read real quotes from published authors. 